\title{
Rabdomiolisis asociada al tratamiento con valaciclovir
}

\author{
valaciclovir-associated rhabdomyolysis
}

\author{
Héctor Enríquez Gómez, Javier De La Fuente Aguado, Laura González Vázquez, María Soledad Rodríguez Pecci. \\ Servicio de Medicina Interna. Hospital POVISA S.A. Vigo
}

\begin{abstract}
Resumen
La rabdomiolisis es un efecto secundario asociado a un buen número de fármacos, entre ellos los antivirales. Describimos un caso de rabdomiolisis secundaria a valaciclovir, efecto no descrito anteriormente en la literatura, en un contexto clínico muy especial. Se trata de un varón que ingresa por un golpe de calor secundario a la realización de ejercicio físico extremo. Durante su ingreso se comienza tratamiento con valaciclovir por un herpes nasolabial, observándose en los días siguientes una marcada elevación de las cifras de CPK que desaparece con la suspensión del mismo. Proponemos, por tanto, que ante la administración de valaciclovir en situaciones que puedan comportar daño mitocondrial habría que realizar monitorización estrecha de los niveles de CPK.

PALABRAS CLAVE: Rabdomiolisis. Valaciclovir. Efecto secundario. Toxicidad Mitocondrial.
\end{abstract}

Valaciclovir es un análogo de la guanina que actúa inhibiendo la síntesis de DNA viral. Mediante la acción de una hidrolasa se convierte en aciclovir, con actividad frente a virus de la familia herpesviridae.

La afectación muscular por este fármaco es un hecho no descrito en la literatura por lo que hemos creído interesante publicar un caso de rabdomiolisis asociado al uso de valaciclovir en un contexto clínico peculiar.

\section{Caso clínico}

Varón de 37 años, sin antecedentes médicos de interés, que ingresó en UCI debido a un golpe de calor secundario a la realización de ejercicio físico intenso (media maratón Vigo-Bayona) precisando intubación orotraqueal. En la exploración física en el Servicio de Urgencias estaba estuporoso, agitado, con sudoración profusa y un Glasgow de 8. La presión arterial era de 130/50 mmHg, la temperatura axilar de $40^{\circ} \mathrm{C}$ y la frecuencia cardiaca de $82 \mathrm{lpm}$. El resto del examen físico fue normal. La analítica mostró: hemoglobina $14.5 \mathrm{~g} / \mathrm{dl}$, leucocitos de $9.370 / \mathrm{mm}^{3}$ con fórmula normal, plaquetas $225.000 / \mathrm{mm} 3$, glucosa $219 \mathrm{mg} / \mathrm{dl}$, urea $53 \mathrm{mg} / \mathrm{dl}$, creatinina $2.20 \mathrm{mg} / \mathrm{dl}$, filtrado glomerular estimado por MDRD 36 ml/minuto, sodio $140 \mathrm{mEq} / \mathrm{l}$, potasio 4,6 mEg/l, AST 47UI//, ALT 45 UI/I, CPK 343 UI/I. El estudio de coagulación fue normal.

A las 24 horas el paciente se encontraba consciente, orientado, colaborador, con amnesia del episodio y se procedió a la extubación. Una nueva analítica mostró: CPK 4.202 UI/I, AST 293 UI/I, ALT $194 \mathrm{UI} / /$, hemoglobina $12.4 \mathrm{~g} / \mathrm{dl}$ y plaquetas $52.000 / \mathrm{mm}^{3}$. La actividad de protrombina era del $49 \%$ y el tiempo de tromboplastina de 19.2 segundos.

A las 72 horas se traslada a la planta de Medicina Interna apreciándose un herpes nasolabial extenso, por lo que se inicia tra-

\begin{abstract}
Rhabdomyolysis is a side effect associated with many drugs, including antivirals. We describe a case of rhabdomyolysis secondary to valaciclovir, an effect not previously described in the literature, in a special clinical setting. This is a man who was admitted for heat stroke secondary to realization of extreme physical exercise. During admission the patient started treatment with valacyclovir for herpes simplex, detecting in the following days a marked elevation of CPK figures that disappear with the suspension. We therefore propose that in the administration of valaciclovir in situations that may involve mitochondrial damage we would be to do close monitoring of CPK levels.

KEYWORDS: Rhabdomyolysis. Valaciclovir. Adverse effect. Mitochondrial toxicity.
\end{abstract}

tamiento con valaciclovir a dosis de 500 mg. cada 12 horas con mejoría de las lesiones. En los días consecutivos se observa un aumento en las cifras de creatinina fosfoquinasa que hacen límite en $35.814 \mathrm{UI} / \mathrm{I}$ en ausencia de síntomas clínicos o deterioro de la función renal. Se decide suspender el fármaco, al no existir otros tratamientos potencialmente causantes, observándose una brusca y marcada disminución de las mismas (figura 1), no presentando complicaciones ulteriores.

\section{Discusión}

El golpe de calor se caracteriza por manifestaciones clínicas a múltiples niveles: sistema nervioso central, cardíaco, pulmonar, endocrino, renal, tracto gastro-intestinal y muscular. A nivel muscular se caracteriza por la producción de rabdomiolisis que también contribuye al daño renal por afectación tubular. En la práctica clínica, el seguimiento se realiza mediante la determinación de CPK. Es conocido que el pico enzimático se alcanza entre las 6 y las 24 horas del inicio del cuadro para descender hasta un $40 \%$ del valor inicial a las 72 horas ${ }^{1}$. Este hecho se puede observar en la evolución temporal de la determinación enzimática de nuestro paciente que se refleja en la tabla 1.

Valaciclovir es un análogo de la guanina que actúa inhibiendo la síntesis de DNA viral. Mediante la acción de una hidrolasa se convierte en aciclovir, con actividad frente a virus de la familia herpesviridae. Entre las reacciones adversas descritas con el empleo de este fármaco, según figuran en su ficha técnica, se encuentran: cefalea, mareos, confusión, alucinaciones, disminución del nivel de conciencia, temblor, agitación, ataxia, convulsiones, encefalopatía, síntomas 


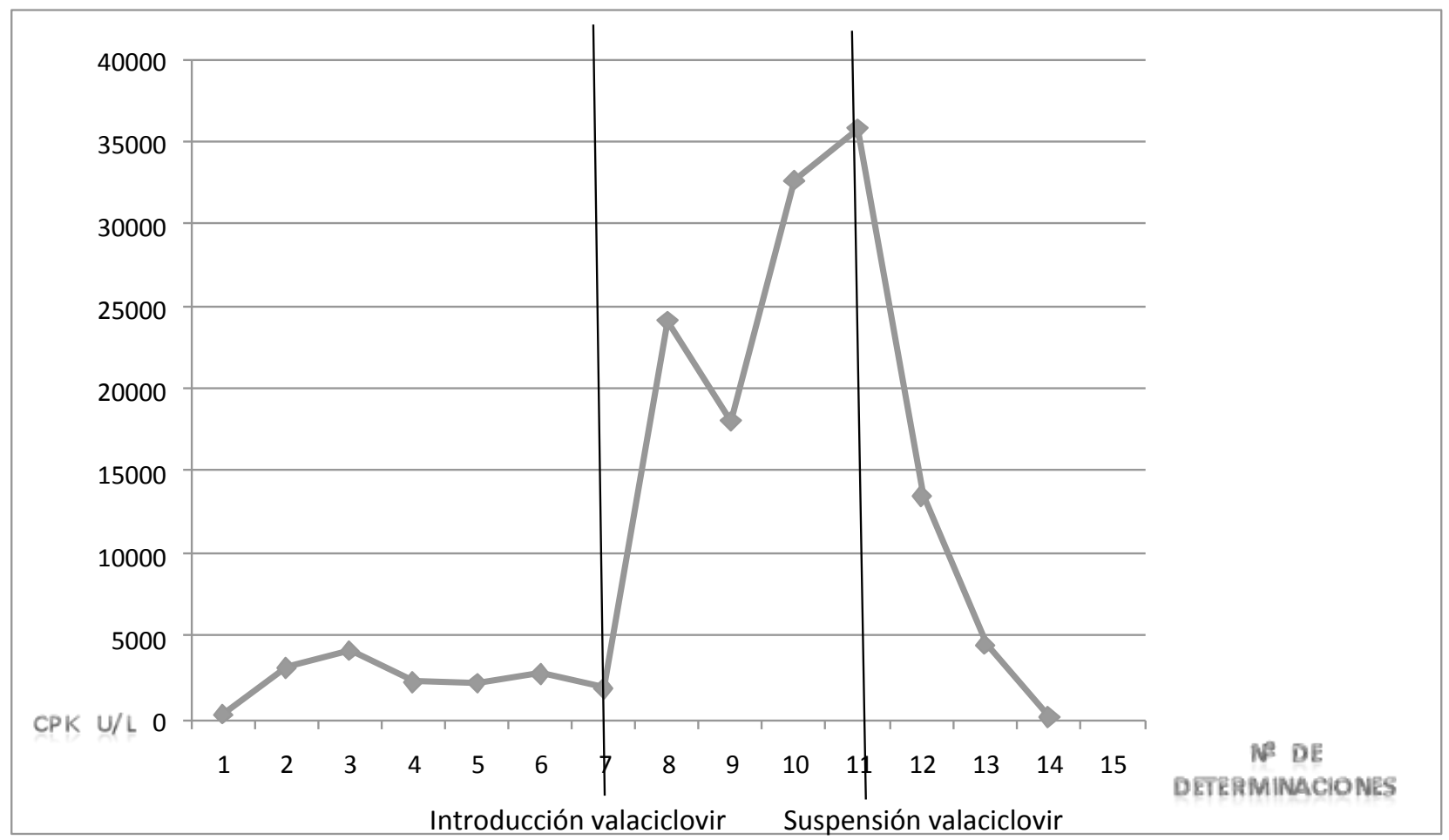

psicóticos, náuseas, vómitos, diarrea, malestar abdominal, aumento reversible de los test de función hepática, disnea, leucopenia, trombocitopenia, erupciones cutáneas, prurito, urticaria, angioedema, e insuficiencia renal aguda.

La rabdiomiolisis es un efecto secundario asociado a un buen número de fármacos, entre ellos los antivirales ${ }^{2} y$, especialmente, los análogos nucleósidos inhibidores de la transcriptasa inversa empleados en el tratamiento de la infección por $\mathrm{VIH}-1^{2,3,4,5}$. En estos casos, el mecanismo propuesto es la inhibición de la síntesis de DNA mitocondrial ${ }^{2,3,6}$ lo que provocaría alteraciones en el equilibrio red-ox, la fosforilación oxidativa y la obtención de energía por parte de la célula ${ }^{2,3,7}$. En el paciente bajo discusión, el daño mitocondrial estaría ya presente al haber sufrido una anaerobiosis mantenida tras el esfuerzo extremo, alterándose la producción de ATP por parte de la mitocondria y encontrándose en estado de acidosis láctica. Dicho sustrato sería en nuestra opinión el factor que podría haber facilitado o desencadenado la toxicidad mitocondrial por parte del valaciclovir con el consiguiente agravamiento de la rabdomiolisis tan evidente.

En el presente caso, según el algoritmo de causalidad del Sistema Español de Farmacovigilancia (modificado de Karch-Lasagna), la reacción adversa (RA) se define como "posible", ya que hubo secuencia temporal evidente, la RA no está previamente publicada (se realizó una búsqueda en
MEDLINE con los términos MESH "Valacyclovir" y "rhabdomyolysis"), no existe causa alternativa que la explique y la alteración en la creatinina fosfoquinasa mejoró tras la retirada del fármaco ${ }^{8}$. Se comunicó el caso al Sistema Español de Farmacovigilancia ${ }^{9}$.

En conclusión, cuando se administra valaciclovir en situaciones que puedan comportar un daño mitocondrial debería efectuarse una estrecha vigilancia clínica y determinación de los niveles séricos de CPK.

\section{Bibliografía}

1. Helena Lappalainen, MD; Eero Tiula, MD, PhD; Lasse Uotila, MD, PhD; Matti Mänttäri, $\mathrm{MD}, \mathrm{PhD}$. Elimination kinetics of myoglobin and creatine kinase in rhabdomyolysis: Implications for follow up. Crit Care Med 2002 Vol. 30, No. 10.

2. Lewis, W, Dalakas, MC. Mitochondrial toxicity of antiviral drugs. Nat Med 1995; $1: 417$.

3. Carr, A, Cooper, DA. Adverse effects of antiretroviral therapy. Lancet 2000; 356:1423.

4. Dalakas, MC, Illa, I, Pezeshkpour, GH, et al. Mitochondrial myopathy caused by longterm zidovudine therapy. N Engl J Med 1990; 322:1098.

5. Moyle, G. Clinical manifestations and management of antiretroviral nucleoside analog-related mitochondrial toxicity. Clin Ther 2000; 22:911.

6. Brinkman, K, Kakuda, TN. Mitochondrial toxicity of nucleoside analogue reverse transcriptase inhibitors: a looming obstacle for long-term antiretroviral therapy? Curr Opin Infect Dis 2000; 13:5.

7. Betteridge, DJ. What is oxidative stress? Metabolism 2000; 49:3.

8. Meyboom RHB, Royer RJ. Causality classification at pharmacovigilance centers in the European community. Pharmacoepidemiol Drug Safety. 1992;1:87-9.

9. Semeprea E, Palopb V, Bayónc A, Sorandod R, Martínez-Mire I. Calidad de la publicación de reacciones adversas a medicamentos en la sección de Cartas al Director de cuatro revistas españolas de medicina interna y medicina general. Aten Primaria. 2006;37:187-94. 